ИЗВЕСТИЯ АКАДЕМИИ НАУК ЭСТОНСКОИ ССР. ТОМ 28 ГЕОЛОГИЯ. 1979, № 3

\title{
НОВЫЕ ДАННЫЕ О РАСПРОСТРАНЕНИИ БРАХИОПОД В ЙХВИСКОМ ГОРИЗОНТЕ СЕВЕРНОЙ ЭСТОНИИ
}

Уточнение состава и распространения фауны, характеризующей среднеордовикский йыхвиский горизонт $\left(\mathrm{D}_{\mathrm{I}}\right)$ Северной Эстонии, весьма актуально. Макрофауна этого горизонта довольно хорошо известна по материалам из обнажений, охватывающих обычно лишь нижние $3-4$, а в каменоломне Алувере - 6,22 м (см. Рымусокс, 1970, с. 224-232). Фауна средней и верхней частей горизонта изучена лишь по немногим обнажениям, поэтому особый интерес представляет исследование разрезов скважин, находящихся в непосредственной близости от района выходов, где йыхвиский горизонт достигает наибольшей мощности.

В данной статье изложены результаты изучения таксономического состава и распространения брахиопод и сопутствующих им представителей некоторых других групп организмов в йыхвиском горизонте по разрезам скв. Пагари, Саку (№ 1098А) и № 1064 (расположена к северу от пос. Вазалемма) и некоторых обнажений, в том числе стратотипического разреза каменоломни Кямбемяэ (рис. 1). Отобранные для изучения фауны образцы породы обрабатывались гипосульфитом натрия в целях извлечения фоссилий. Установлено, что в йыхвиском горизонте наиболее часто встречаются иглокожие (в частности криноидеи, представленные разрозненными фрагментами скелета) и брахиоподы (рис. 2-4). Находки трилобитов крайне редки (данные о встречаемости мшанок не учитывались). Исходный материал недостаточен для обсуждения вопросов, касающихся принятых условных границ йыхвиского горизонта (см. Мянниль, 1958, 1963, 1966; Рыымусокс, 1970), но он позволяет уточнить таксономический состав фауны и проследить некоторые уровни обновления видового состава в пределах этого горизонта. Один из таких уровней может иметь биостратиграфическое значение при корреляции разрезов.

Рис. 1. Карта буровых скважин (кружки) и обнажений (треугольники). Прерывистыми линиями обозначены изолинии мощности йыхвиского горизонта (данные Л. Пылма).

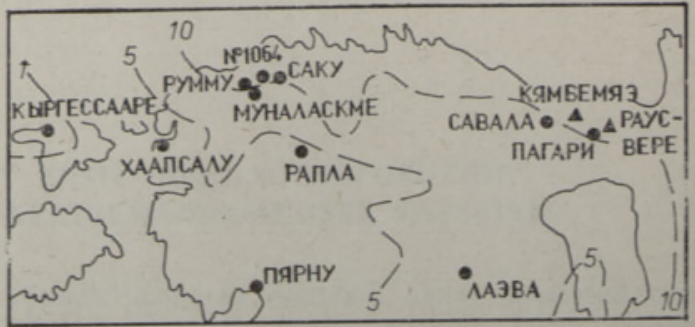




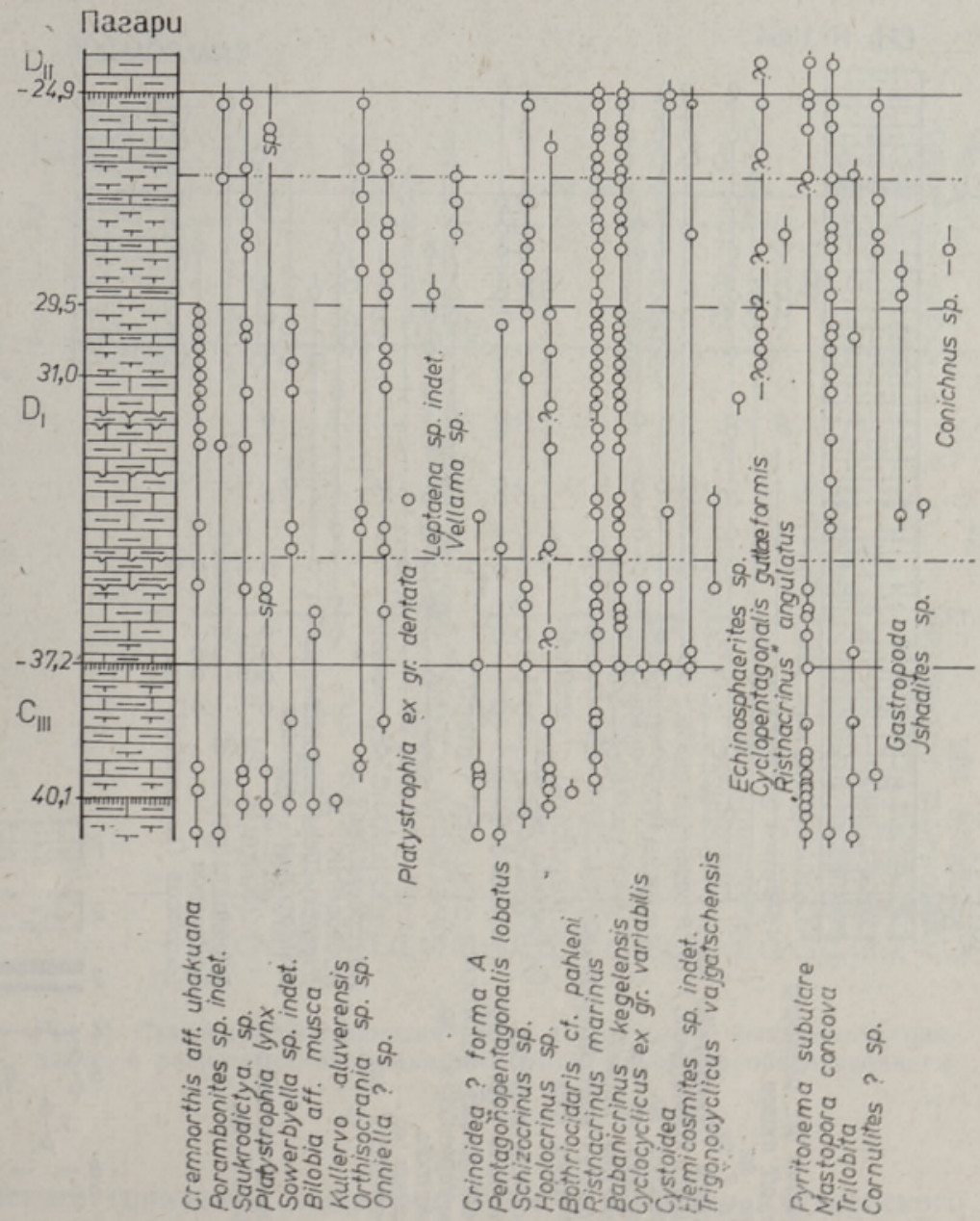

Рис. 2. Схема распространения видов в йыхвиском горизонте разреза скв. Пагари. Литологическая характеристика разреза приведена в обобщенном виде по данным Л. Пылма (также на рис. 3). Условные обозначения см. на рис, 3.

По разрезам, изученным как в западной, так и в восточной частях Северной Эстонии, можно сказать, что для йыхвиского горизонта характерно наличие мелких брахиопод родов Cremnorthis, Saukrodictya и Onniella?, члеников стеблей иглокожих Ristnacrinus marinus Öpik, Babanicrinus kegelensis (Yeltyscheva), Trigonocyclicus vajgatshensis Yeltyscheva, Cyclopentagonalis sp. (см. также Елтышева, 1966, с. 69), водорослей Mastopora concava Eichw. и некоторых других видов (рис. 2 -4). Редко встречаются брахиоподы родов Clitambonites, Leptaena, Platystrophia и другие, которые обычно считаются характерными для горизонта. Среди установленных брахиопод обращает на себя внимание род Cremnorthis, который в Северной Эстонии появляется в ухакуском горизонте (С тельно в средней части йыхвиского горизонта.

$\mathrm{B}$ анализируемых в настоящей работе разрезах скважин род Cremnorthis исчезает в нижней части наиболее глинистого комплекса слоев 


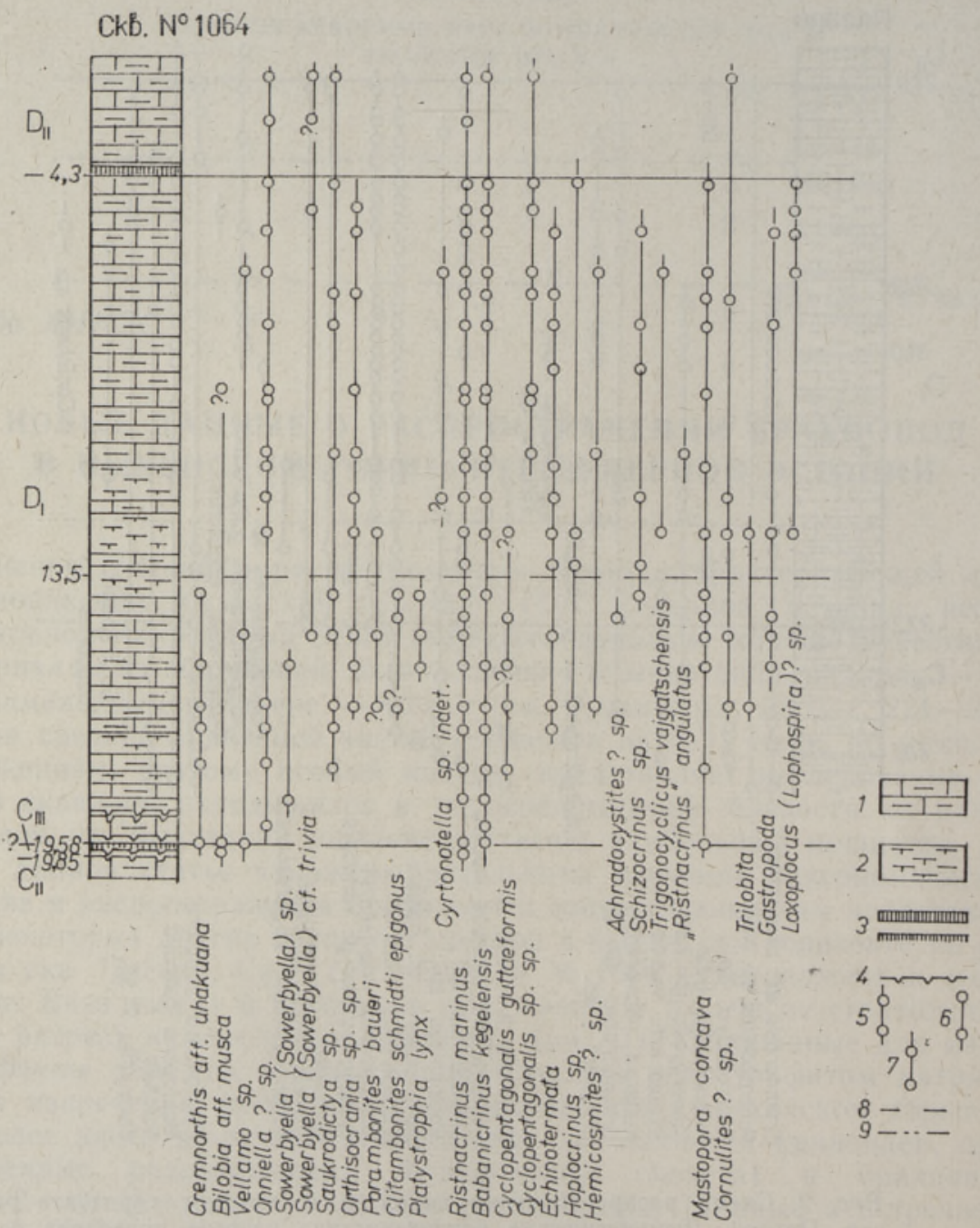

Рис, 3. Схема распространения вндов в йыхвиском горизонте разреза скв. № 1064. 1 - глинистые детритовые известняки; 2 - карбонатные детрнтовые мергели; 3 - прослой метабентонита; 4 - поверхность перерыва; 5 - переходящие виды; 6 - виды предположительно не переходящие в вышележащий горнзонт; 7 - виды, предположительно появляющиеся в йыхвиском горизонте; 8 - уровень исчезновения Cremnorthis; 9 - уровень, ограничивающнй слои с Pyritonema.

йыхвиского горизонта (пагариская пачка; Григялис, 1978). При этом в восточной части Северной Эстонии мощность слоев с Cremnorthis несколько больше (в скв. Пагари 7,2 м), чем в западной части (в скв. Саку около 4 м, в скв. № 10645,6 м). Какие изменения происходят в видовом составе фауны на уровне последних находок Cremnorthis, еще не вполне ясно. Из видов, установленных нами ниже или выше этой границы, следует отметить Clitambonites schmidti epigonus Öpik и Echinosphaerites sp. (см. рис. 2, 3). Обе названные формы, как и Cremnorthis, следует рассматривать как старые элементы фауны. По В. Яануссону (Jaanusson, 1945), последние, т. е. элементы «фаун с Leptelloidea musca и Pseudocrania depressa», характеризуют нижнюю часть 


\section{Кямбемяз}
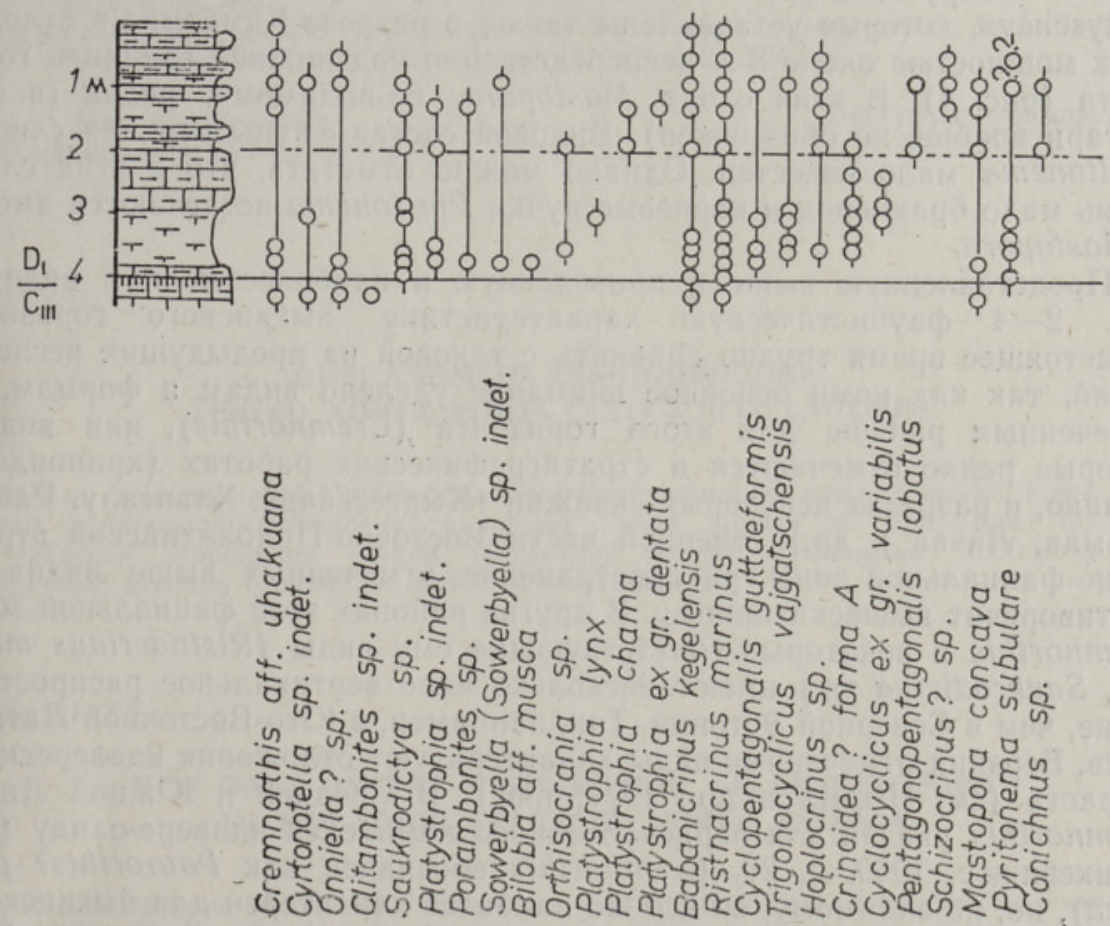

Рис. 4. Схема распространения видов в стратотипе йыхвиского горизонта, в разрезе каменоломни Кямбемяэ. Условные обозначения см. на рис. 3.

йыхвиского горизонта, выделенную им в качестве алувереского подгоризонта и изученную наиболее детально по разрезам из района Пяэскюла. Недалеко от этого района, в скв. Саку мощность йыхвиского горизонта достигает $10,15 \mu$ (интервал $35,7-45,85$ м), и последние находки Cremnorthis происходят из образца, отобранного на глубине 41,9 м, т. е. на 3,95 м выше нижней границы горизонта. В разрезе скв. № 1064 мощность слоев с Cremnorthis достигает $5 \mu$, что соответствует мощности алувереской пачки (см. Григялис, 1978) в этом районе. Сравнение мощностей слоев с Cremnorthis на западе и на востоке позволяет предполагать, что в каменоломне Алувере обнаженные отложения йыхвиского горизонта, содержащие богатый комплекс макрофауны (см. Рымусокс, 1970, табл. 13), или полностью соответствуют слоям с Cremnorthis, или отмеченный род исчезает в пределах верхнего метра разреза. В пользу последнего предположения говорит присутствие метабентонитоподобного прослоя в верхней части разреза Алувере (см. Рыымусокс, 1970, с. 229) и такого же прослоя в разрезе скв. № 1064 несколько выше последних находок Cremnorthis. Возможно, что этот прослой соответствует слою метабентонита $c$, по индексации Э. Юргенсон (1958), установленному во многих разрезах скважин Северной Эстонии.

Видовой состав фауны йыхвиского горизонта в разрезе скв. Пагари отличается от такового других разрезов присутствием корневых пучков Pyritonema subulare в верхах и низах горизонта (соответственно в интер- 
валах 24,9-26,5 и около $35-36,8$ м). В нижних слоях наряду с Pyritonema обнаружены еще Bilobia musca и Cyclocyclicus ex. gr. variabilis Yeltyscheva, которые установлены также в разрезе Кямбемяэ в отложениях мощностью около $2 \mu$ непосредствснно над нижней границей горизонта (рис. 4). В этих слоях Mastopora, по-видимому, редок (в скв. Пагари вообще не обнаружен). Видовой состав фауны верхних слоев с Pyritonema мало известен. Однако можно отметить, что в этих слоях очень мало брахиопод и корневые пучки Pyritonema встречаются вместе c Mastopora.

Представленную выше и приведенную в наиболее полном виде на рис. 2-4 фаунистическую характеристику йыхвиского горизонта в настоящее время трудно сравнить с таковой из предыдущих исследований, так как нами основное внимание уделено видам и формам, не отмеченным раньше для этого горизонта (Cremnorthis), или видам, которые редко отмечаются в стратиграфических работах (криноидеи). Однако, в разрезах некоторых скважин (Кыргессааре, Хаапсалу, Рапла, Эйамаа, Лаэва и др.) северной части Восточно-Прибалтийской структурно-фациальной зоны распространение отмеченных выше видов не противоречит вышесказанному. В других районах этой фациальной зоны Cremnorthis и некоторые сопутствующие ему виды (Ristnacrinus marinus, Saukrodictya sp.) имеют несколько иное вертикальное распространение, чем в Северной Әстонии. Так, например, в Юго-Восточной Латвии в скв. Берзини отмеченные виды характеризуют отложения идавереского возраста (см. Пылма и др., 1977, рис.). В Средней и Южной Литве Cremnorthis указан для нерасчлененного комплекса идавере-оанду (см. Пашкевичюс, 1959, с. 20, Cremnorthis обозначен как Paurorthis? prenaica), но, по-видимому, он все же наиболее характерен для йыхвиского горизонта (см. Мянниль, 1966, рис. 24, Cremnorthis обозначен как «Dalmanella» n. sp. a).

Автор очень признателен геологам из Управления геологии ЭССР В. Юргенсону и А. Хаасу, предоставившим возможность изучения и опробования кернов скв. Саку и № 1064.

\section{Л ИТЕРА Т Р А}

Григялис А. А. (ред.) Региональная стратиграфическая схема ордовикских отложений Прибалтики. - В кн.: Решения межведомственного регионального стратиграфического совещания по разработке унифицированных стратиграфических схем Прибалтики 1976 г. с унифицированными стратиграфическими корреляционными таблицами. Л., 1978.

Елты шев а P. С. Стебли ордовикских морских лилий Прибалтики (средний ордовик). - Вопросы палеонтологин, 1966, т. V, с. $53-70$.

М яннил ь Р. М. Основные черты стратиграфии кейлаского горизонта (DII, ордовик) в Эстонин. - Изв. АН ЭССР. Сер. техн. и физ.-мат. наук, 1958, т. VII, № 3 , c. $235-246$.

М янни ль Р. М. Вопросы сопоставления ордовикских отложений Эстонии и Ленинградской области. - Тр. Ин-та геол. АН ЭССР, 1963, т. Х, с. 3-39.

М янни ль Р. М. Нстория развития Балтийского бассейна в ордовике. Таллин, 1966.

П а ш кевич ю с И. Ю. Ордовик (О). - В кн.: Краткий очерк геологни Литовской ССР. Вильнюс, 1959 , с. $17-23$.

Пыл м а Л., С а р в Л., Х и н т с Л. Расчленение ордовикских отложений разреза скв. Берзини (Юго-Восточная Латвня). - Изв. АН ЭССР. Хим. Геол., 1977, т. 26. № 2, c. $113-121$.

Р ы м у сокс А. Стратиграфия вируской и харьюской серий (ордовик) Северной Эстонии. І. Таллин, 1970.

Хинтс Л. Брахиоподы родов Cremnorthis и Paurorthis из среднего ордовика Эстонии. - Изв. АН ЭССР. Хим. Геол., 1968, т. 17, № 4, с. $386-392$. 
Ю рген нон Э. А. Метабентониты Эстонской ССР. - Тр. Ин-та геол. АН ЭССР, 1958, T. II, c. $73-85$.

J a a nus son, V. Ober die Stratigraphie der Viru- resp. Chasmops-Serie in Estland. Geol. Fören. Förhandl., 1945, Bd. 67, H. 2, S. 212-224.

\title{
Ннститут геологии \\ Академии наук Эстонской ССР
}

Поступила в редакцию 29/XII 1978

\section{Linda HINTS}

\section{UUSI ANDMEID BRAHHIOPOODIDE LEVIKU KOHTA PŌHJA-EESTI JÖHI LADEMES}

Artiklis on iseloomustatud jõhvi lademe sisest fauna muutust, mida markeerib kõige ilmekamalt brahhiopoodi Cremnorthis kadumine. Fauna muutus nii Põhja-Eesti ida- kui ka lääneosa läbilõigetes langeb tõenäoliselt kokku lademesisese metabentoniidikihiga ning kivimite litoloogilise iseloomu muutumisega.

\section{Linda HINTS}

\section{NEW DATA ON THE DISTRIBUTION OF BRACHIOPODS IN THE JOHVI STAGE OF NORTH ESTONIA}

\begin{abstract}
The studied sections of the Jonhvi Stage are characterized first of all by the occurrence of brachiopods Cremnorthis, Saukrodictya, Onniella?, fragments of stalks of crinoids Ristnacrinus, Babanicrinus, etc., and the alga Mastopora.

The change in the species composition within the stage is most clearly marked by the distribution of Cremnorthis, which has been stated only in the lowermost part. On the basis of the data presented in the article, it may be supposed that the level of the disappearance of Cremnorthis is of a correlational significance, at least within the limits of North Estonia. Apart from that, this level probably corresponds, in general lines, to the thin metabentonite layer that might also mark the boundary between the Pagari and Aluvere members,
\end{abstract}

